\title{
About breaking barriers, the risk paradox, and other twists
}

\author{
Jan K. Buitelaar
}

Published online: 17 May 2011

(c) The Author(s) 2011. This article is published with open access at Springerlink.com

Acquiring new knowledge requires many times to break through old barriers and disregard conventional perspectives. Thus, the old classification scheme of attentiondeficit/hyperactivity disorder (ADHD) in the DSM-IV stipulated that the symptoms of ADHD might not occur exclusively during the course of pervasive developmental disorder (PDD). Although understandable from a point of view to maximally differentiate ADHD from PDD or autism spectrum disorder (ASD), the classification rule simply ignored clinical reality of the large clinical overlap between ADHD and ASD and has blocked research into the neurobiological underpinnings thereof for many years [7, 8]. In a similar vein, the DSM-IV prohibited to classify oppositional defiant disorder (ODD) when also criteria for conduct disorder (CD) were met. This DSM-IV rule was in marked contrast with the classification of ODD and CD in the ICD-10 nomenclature, where both ODD and CD symptoms were lumped together into one overall category of CD. As a consequence, the DSM-IV system blocked the refined study of the relationships between ODD and CD and did also impediment the study of the added clinical value of diagnosing ODD symptoms in patients with CD. In their carefully conducted longitudinal study of the developmental relations between ODD and CD, Diamantopoulou et al. [2] assessed symptoms of ODD and CD in a community-based sample. They found that ODD and CD symptoms developed rather independently over time, and that ODD symptoms did not increase the risk for later developing $\mathrm{CD}$, except for when already subthreshold CD

\section{J. K. Buitelaar $(\square)$}

Department of Cognitive Neuroscience, Radboud University Nijmegen Medical Center, Karakter Child and Adolescent Psychiatry, P.O. Box 9101, 6500 HB Nijmegen, The Netherlands e-mail: j.buitelaar@psy.umcn.nl symptoms were present. The findings did not support the idea that ODD symptoms are a milder or earlier form of CD. Further, the presence of ADHD did not make a difference in increasing the transition rate from ODD to CD, at least in this community sample. What is our next research step? This should further renew and bolster our interest in the study of the phenomenology, aetiology and neurobiology of ODD as separate from CD, as has already been started $[9,10]$.

This issue presents another longitudinal study of the development of CD symptoms in a community [4]. Taking the perspective of social information processing as key to understanding distorted patterns of social interaction and rule transgressions, Ha et al. showed that mentalizing style of both children and parents independently contributed to the development of $\mathrm{CD}$. In particular mothers who were rather inaccurate in reading their child's mental state and children who displayed a systematic unrealistic and positive bias with strong self-reference were much more likely to have CD symptoms. Since the parent-child interaction has found to be central to the development of child mentalizing capacities, these data point to the continued importance to examine the role of early parenting factors and parent-child fit in the development of CD.

Two other papers in this issue add to our knowledge on the not to be underestimated problem of substance use in children with psychiatric disorders. Diaz et al. [3] report that among a clinically referred sample of adolescents in an urban setting about $10 \%$ had a cannabis use disorder and about $4 \%$ an alcohol use disorder, whereas half of the sample appeared to use alcohol or substances occasionally. It does not surprise that the main predictors were high rates of aggressive and antisocial behaviour and thought problems. Kepper et al. [5] examined the prevalence of substance use problems in another group of vulnerable 
children, i.e. children in special education and in residential youth care. Between 16-22\% of adolescents in special education and youth care were already daily smokers at 12-13 years of age, which is compared to $1 \%$ daily smokers in their counterparts in mainstream education a huge increased risk. In terms of risk factors, the usual suspects were identified as ethnicity and socio-economic status and other family variables. However, as the authors pointed out clearly, this was not the whole story. The most exciting finding was that of the risk paradox: those adolescents who would not have been at risk given normal circumstances, appeared to be at higher risk when placed in special education or youth care. Read the paper for a discussion of the possible explanations of these findings. Suffice here to stress the implications of these findings for screening, early identification and intervention of substance use problems and disorders in vulnerable adolescents.

Defining paradoxes boosts our thinking about difficult problems. Recall the prevention paradox: many more cases come from the majority of subjects in the population at low-risk status than from the fewer cases with high-risk status. This means that interventions targeted at reducing the general level of risk exposure in the population will ultimately be more efficient in lowering caseness than a strategy of identifying and treating the high-risk individuals only. Think about the obesity paradox: whereas overweight is a risk factor for cardiovascular problems and increased mortality in general, among cardiovascular patients overweight is associated with reduced mortality [6]. One explanation is that the impact of a risk factor is context-dependent and that the impact may be off-set by other risk factors, and another that many non-linear relations between risk factors may occur.

Finally consider Peto's paradox: The evolution of multicellularity required the suppression of cancer. If every cell has some chance of becoming cancerous, large, longlived organisms should have an increased risk of developing cancer compared with small, short-lived organisms. However, there appears to be no correlation between body size and cancer risk and this is known as Peto's paradox [1]. Animals with 1,000 times more cells than humans do not exhibit an increased cancer risk, suggesting that natural mechanisms can suppress cancer 1,000 times more effectively than is done in human cells. Thus, obviously and compellingly, our efforts at cancer prevention should be directed to understand how evolution has suppressed cancer to develop ultimately improved cancer prevention in humans.

Who takes the challenge and transforms cute observations into pointing paradoxes that help us to solve the many problems in the field of child and adolescent mental health?

Open Access This article is distributed under the terms of the Creative Commons Attribution Noncommercial License which permits any noncommercial use, distribution, and reproduction in any medium, provided the original author(s) and source are credited.

\section{References}

1. Caulin AF, Maley CC (2011) Peto's Paradox: evolution's prescription for cancer prevention. Trends Ecol Evol 26(4):175-182

2. Diamantopoulou S, Verhulst F, van der Ende J (2011) The parallel development of ODD and CD symptoms from early childhood to adolescence. Eur Child Adolesc Psychiatry. doi: 10.1007/s00787-011-0175-3

3. Diaz R, Goti J, García M, Gual A, Serrano L, Gonzalez L, Calvo R, Castro-Fornieles J (2011) Patterns of substance use in adolescents attending a mental health department. Eur Child Adolesc Psychiatry. doi:10.1007/s00787-011-0173-5

4. Ha C, Sharp C, Goodyer I (2011) The role of child and parental mentalizing for the development of conduct problems over time. Eur Child Adolesc Psychiatry. doi:10.1007/s00787-011-0174-4

5. Kepper AS, Monshouwer K, van Dorsselaer S, Vollebergh W (2011) Substance use by adolescents in special education and residential youth care institutions. Eur Child Adolesc Psychiatry. doi:10.1007/s00787-011-0176-2

6. McAuley PA, Blair SNJ (2011) Obesity paradoxes Sports Sci. 11:1-10 (Epub ahead of print)

7. Rommelse NN, Franke B, Geurts HM, Hartman CA, Buitelaar JK (2010) Shared heritability of attention-deficit/hyperactivity disorder and autism spectrum disorder. Eur Child Adolesc Psychiatry 19(3):281-295

8. Rommelse NN, Geurts HM, Franke B, Buitelaar JK, Hartman CA (2011) A review on cognitive and brain endophenotypes that may be common in autism spectrum disorder and attention-deficit/ hyperactivity disorder and facilitate the search for pleiotropic genes. Neurosci Biobehav Rev 35(6):1363-1396

9. Stringaris A, Goodman R (2009) Three dimensions of oppositionality in youth. J Child Psychol Psychiatry 50(3):216-223

10. Stringaris A, Maughan B, Goodman RJ (2010) What's in a disruptive disorder? Temperamental antecedents of oppositional defiant disorder: findings from the Avon longitudinal study. Am Acad Child Adolesc Psychiatry 49(5):474-483 